\title{
EDITORIAL
}

\section{Eosinophils in eosinophilic pneumonia}

\author{
C. Albera, P. Ghio
}

Idiopathic eosinophilic pneumonia (IEP) is an uncommon disease of unknown aetiology characterized by the accumulation of eosinophils in the lung, variable blood eosinophilia and peripheral opacities on the chest radiogram. The response to steroid treatment is dramatic but relapses are frequent, requiring the use of long-term steroid treatment [1].

Eosinophils are primarily tissue cells, containing in their granules many preformed proinflammatory and cytotoxic mediators [2]. They are also able to synthesize many other substances that defend the host against exogenous stimuli [3]; under normal conditions the eosinophil number in those tissues that have contact with the environment is 200-400 times greater than in the blood [4]. An abnormally high accumulation of these cells within the lung, frequency reaching up to $50 \%$ of the total alveolar cell population [5], is the hallmark of IEP, but the role of the eosinophil in the immunopathogenesis of lung damage in this disorder is still not completely elucidated [4].

Eosinophils accumulated within both interstitium and small air spaces [1] are hypodense and widely degranulated cells. They show typical morpho-functional characteristics of activated cells and are able to damage parenchymal lung structures by releasing a variety of toxic substances [6]. Consequently, two major points need to be investigated and discussed: 1) how do eosinophils cause parenchymal injury? 2) how are eosinophils recruited and activated at the site of inflammation?

\section{Eosinophils as effector cells in mediating lung damage}

Cytotoxic mediators secreted by eosinophils are either preformed, stored in specific eosinophilic granules and released after activation (major basic protein (MBP), eosinophilic cationic protein (ECP), eosinophil derived neurotoxin (EDN), eosinophil peroxidase (EPO), collagenase, arylsulphatase $\mathrm{B}$, beta-glucuronidase) or synthesized de novo after activation (lipid-derived mediators, oxygen reactive metabolites, cytokines, neuropeptides) [3].

Of the preformed molecules, ECP seems to play the most important role in the pathogenesis of lung damage in IEP. In fact there is clear evidence of increased alveolar levels of ECP in patients with IEP, especially in chronic disease (chronic eosinophilic pneumonia

Correspondence: C. Albera, University of Turin, Clinical and Biological Sciences Department, San Luigi Gonzaga Hospital, Regione Gonzole 10, 10043 Orbassano, Turin, Italy.
(CEP)) [7-9]. The finding of a significant correlation between ECP levels and eosinophil numbers in bronchoalveolar lavage fluid (BALF) reported by SHIJUBO and co-workers [7] underlines the strong relationship between the degree of eosinophilic inflammation and the burst of eosinophil-derived toxic mediators. However, BoOmars and co-workers [8] in this issue of the Journal did not find such a correlation when evaluating 12 patients with CEP. They attributed this to different proportions of activated eosinophils being present within the alveolar spaces in individual patients. The significance of these mediators in the pathogenesis of IEP and other eosinophil-mediated diseases is underlined by the observation that ECP levels measured in BALF in patients with pulmonary eosinophilic granuloma are normal [7]. In fact, in this disease the eosinophil is thought to be present in the alveolar compartment only as an accompanying cell, whereas the pivotal cell in the pathogenesis of lung damage is the Langerhans cell [10]. The observation of increased ECP levels in BALF of idiopathic pulmonary fibrosis, which was related to the decline in lung function [11], also suggests a possible role of this mediator in the pathogenesis of this disease.

\section{Recruitment and activation of eosinophils}

There is increasing evidence that recruitment and activation of eosinophil within lung tissues is under the control of mononuclear cells. T-lymphocytes are the source of lymphocyte chemoattractant factor (LCF) [12] and interleukin (IL)-2 [13], the two most potent eosinophil chemoattractants. Cytokines of the TH-2 subtype (IL-3, IL-4, IL-5 and granulocyte macrophage colony stimulating factor (GM-CSF)) regulate both recruitment and activation of eosinophils [14].

The role of T-lymphocytes in modulating the eosinophilic component of the alveolitis is supported by the fact that memory and activated alveolar CD4+ T-lymphocytes are increased in BALF of IEP $[15,16]$. This is underlined in a study by AzUMA and co-workers [17] in this issue of the Journal; they found a correlation between the number of activated T-lymphocytes and the number of eosinophils in BALF. Similar findings, as well as a correlation with the severity of the disease, were also found in asthma [18].

The analysis of the secretory profile of these activated T-cells, performed by evaluating cytokine levels in BALF, showed that the recruitment of eosinophils in IEP patients could be related to an overproduction of IL-2 (TH-1 profile) inducing a secondary increase of 
IL-5 (TH-2 profile) [19, 20], as was found in patients treated with high doses of recombinant IL-2 [21]. These findings could offer an explanation for the high intensity eosinophilic alveolitis observed in IEP, a disease without a clear TH-2 profile [17]. Furthermore, the increased number of alveolar macrophages in BALF of patients with active IEP $[15,17]$ suggests that mononuclear phagocytes, either directly or by cooperation with alveolar T-lymphocytes, could exert further regulatory activities on both eosinophil recruitment and activation.

The modulation of adhesion molecule expression is another way by which both the influx and the activation of inflammatory cells into the target organs and tissues are regulated. Eosinophils bind to their adhesion ligands in the extracellular matrix and migrate through vascular endothelial cells [22, 23]; they are then activated by binding to fibronectin (in a dose and timedependent manner) leading to degranulation [24] and release of increased amounts of both leukotriene $\mathrm{C}_{4}$ $\left(\mathrm{LTC}_{4}\right)$ [25] and reactive oxygen species [26]. The adhesion to fibronectin and the subsequent activation of eosinophils are dependent upon, and consequently regulated by, the expression of very late activation antigen 4 (VLA-4) on the cell surface [26], and enhanced by soluble intercellular adhesion molecule-1 (ICAM-1) [27]. In addition, the adhesion of eosinophils to fibronectin prolongs their survival [28]. As far as the preferential expression of adhesion molecules on locally accumulated eosinophils in IEP is concerned, it has recently been demonstrated that the expression of certain adhesion molecules (CD11a, CD11b, CD18, CD49d, CD62L) is lower for BALF eosinophils than for circulating ones; the CD54 (ICAM-1) molecule is expressed only by alveolar eosinophils [17].

Peripheral blood eosinophils from both healthy and asthmatic subjects synthesize and release IL-3, IL-5, GMCSF and IL-8 [29-31] after stimulation and, in particular, after chemoattractant challenge [32]. The ability of eosinophils to produce and release these cytokines confirms the role of the activated eosinophil as an effector cell. This cytokine-mediated network, the increase of human leucocyte antigen-DR (HLA-DR) expression on activated eosinophils [15] and the expression of the CD4 molecule by eosinophils [33] suggests that the interaction with activated alveolar antigen presenting cells could also be a pathogenetic mechanism for eosinophil recruitment and activation.

\section{Heterogeneity of eosinophil recruitment and activation}

SAITA et al. [34], by evaluating 5 patients with IEP and peripheral blood eosinophilia, demonstrated that circulating eosinophils show a heterogenous chemotactic response to 5 different T-cell-derived eosinophil chemotactic factors (ECFs). Eosinophils of two patients responded to five ECFs, whereas those of the other three patients failed to respond to one of these ECFs (ECFPI 9). The lack of responsiveness to ECF-PI 9, was associated with a favourable clinical and radiological outcome of the diseases, accompanied by a reduction of lung infiltrating eosinophils after steroid treatment.

KITA et al. [20] recently showed that in IEP the number of eosinophils in affected lobes was 70 times higher than in unaffected ones. This preferential accumulation was accompanied by a corresponding local increase of eosinophil-active cytokines (IL-5, IL-6 and IL-10) which were virtually absent in uninvolved lobes and in peripheral blood.

AlOu et al. [35] observed that eosinophils isolated from BAL in one case of CEP produced high levels of oxygen free radicals and exhibited an increased level of cyclic adenosine monophosphate (cAMP) deaminase phosphodiesterase (PDE). The PDE activity in this patient was preferentially located in the plasma membrane, whilst the PDE activity of eosinophils in asthmatic and healthy subjects was predominantly located in the cytosol. This difference could be due to: a) the presence of a particular PDE isoform that binds to the eosinophil membrane in CEP; b) the presence of an abnormal PDE protein only in CEP; c) a translocation of PDE activity from the cytosol to the membrane during cell activation. The first two hypotheses seem to be the more intriguing ones.

Analysis of above data suggests that this heterogeneity, which is able to influence both the site and the amount of accumulation of eosinophils within the lung, could be related either to the presence of different circulating eosinophil populations or to the generation of clones of T-lymphocytes that preferentially produce different chemoattractants and regulatory molecules. Possible explanations for this heterogeneity include genetic differences, previous eosinophil priming which modified eosinophil structures (adhesion molecules, cell plasticity) and a selective activation of T-cell clones related to an altered accessory function of alveolar mononuclear phagocytes.

A knowledge of the immunological network involving both cells and mediators offers an explanation of the dramatic response of IEP to steroid therapy as well as a suggestion for new therapeutic strategies that could be able not only to rapidly reduce eosinophilic infiltration of parenchymal structures, but also to prevent the frequent relapses and the long-lasting need for steroid treatment, by inhibiting possible self-maintaining eosinophilic inflammation. This aim could be achieved by employing specific cytokine or chemoattractant receptor antagonists, or by acting on other mechanisms such as cAMP PDE activity.

In conclusion, the picture of the pathogenetic role of eosinophils in idiopathic eosinophilic pneumonia, even if frameless and still blurred, is becoming clearer. The eosinophil is the principal effector cell and seems to be involved in both the regulation and the persistence of the inflammatory processes. Alongside the eosinophil, the T-lymphocyte is the cell that primarily regulates both recruitment and activation of the eosinophil. In the background is the alveolar macrophage, which probably plays a regulatory role either directly or by interacting with T-lymphocytes. In the next few years, it is probable that further data will become available that may shed light upon the role of the alveolar macrophage.

\section{References}

1. Carrington CB, Addington WW, Goff AH, et al. Chronic eosinophilic pneumonia. $N$ Engl J Med 1969; 280: 787-798. 
2. Gleich GJ, Adolphson CR. The eosinophil leucocyte: structure and function. Adv Immunol 1986; 39: 177-253.

3. Kroegel C, Virchow Jr JC, Luttmann W, Walker C, Warner JA. Pulmonary immune cells in health and disease: the eosinophil leucocyte (part I). Eur Respir J 1994; 7: 515-543.

4. Lopez M. Eosinophilic pneumonia. Ann Allergy 1993; 71: 338-339.

5. Allen JN, Davis WB. Eosinophilic lung diseases. Am J Respir Crit Care Med 1994; 150: 1423-1438.

6. Gonzales EB, Swedo JL, Rajaraman S, Daniels JC, Grant JA. Ultrastructural and immunohistochemical evidence for release of eosinophilic granules in vivo: cytotoxic potential in chronic eosinophilic pneumonia. $J$ Allergy Clin Immunol 1986; 79: 755-762.

7. Shijubo N, Shigehara K, Hirasawa H, Inuzuka M, Abe $\mathrm{S}$. Eosinophilic cationic protein in chronic eosinophilic pneumonia and eosinophilic granuloma. Chest 1994; 106: $1481-1486$.

8. Boomars KA, van Velzen-Blad H, Mulder PGH, Koenderman L, Lammers J-WJ, van den Bosch JMM. Eosinophilic cationic protein and immunoglobulin levels in bronchoalveolar lavage fluid obtained from patients with chronic eosinophilic pneumonia. Eur Respir $J$ 1996; 9: 2488-2493.

9. Janin A, Torpier G, Courtin P, et al. Segregation of eosinophil proteins in alveolar macrophage compartments in chronic eosinophilic pneumonia. Thorax 1993; 48: 57-62.

10. Hance AJ, Cadranel J, Soler P, Basset F. Pulmonary and extrapulmonary Langerhans cell granulomatosis (histiocytosis X). Semin Respir Med 1988; 9: 349-368.

11. Hallgren R, Bjermer L, Lundgren R, Venge P. The eosinophil component of the alveolitis in idiopathic pulmonary fibrosis. Am Rev Respir Dis 1989; 139: 373397.

12. Cruikshank WW, Berman JS, Theodore AC, Bernado J, Center DM. Lymphocyte chemoattractant factor (LCF) induces CD4-dependent intracytoplasmic signalling in lymphocytes. J Immunol 1991; 146: 2928-2934.

13. Rand TH, Silberstein DS, Kornfeld H, Weller PF. Human eosinophils express functional interleukin-2 receptors. J Clin Invest 1991; 88: 825-832.

14. Weller PF, Lim K, Wan HC, et al. Role of the eosinophil in allergic reactions. Eur Respir J 1996; 9: Suppl 22: $1095-1159$.

15. Albera C, Ghio P, Solidoro P, Mabritto I, Marchetti L, Pozzi E. Activated and memory alveolar T-lymphocytes in idiopathic eosinophilic pneumonia. Eur Respir $J$ 1995; 8: 1281-1285.

16. Walker C, Bauer W, Braun RK, et al. Activated T-cells and cytokines in bronchoalveolar lavages from patients with various lung disease associated with eosinophilia. Am J Respir Crit Care Med 1994; 150: 1038-1048.

17. Azuma M, Nakamura Y, Sano T, Chano Y, Sone S. Adhesion molecule expression on eosinophils in idiopathic eosinophilic pneumonia. Eur Respir J 1996; 9: 2494-2500.

18. Walker C, Kaegi MK, Braun MD, Blasek K. Activated T-cells and eosinophilia in bronchoalveolar lavages from subjects with asthma correlated with disease severity. J Allergy Clin Immunol 1991; 89: 958-967.

19. Yamaguchi Y, Suda T, Shiozaki H, et al. Role of IL-5 in IL-2 induced eosinophilia. In vivo and in vitro expression of IL-5 mRNA by IL-2. J Immunol 1990; 145 : 873-877.
20. Kita H, Sur S, Hunt LW, et al. Cytokine production at the site of disease in chronic eosinophilic pneumonitis. Am J Respir Crit Care Med 1996; 153: 1437-1441.

21. van Haelst Pisani C, Kovach JS, Kita H, et al. Administration of interleukin-2 results in increased plasma concentration of IL-5 and eosinophilia in patients with cancer. Blood 1991; 78: 1538-1544.

22. Neeley SP, Hamann KJ, White SR, Baranowski SL, Burch RA, Leff AR. Selective regulation of expression of surface adhesion molecules Mac-1, L-selectin and VLA-4 on human eosinophils and neutrophils. Am J Cell Mol Biol 1993; 8: 633-639.

23. Laudanna C, Melotti P, Bonizzato C, et al. Ligation of members of the beta- 1 or the beta- 2 subfamilies of integrins by antibodies triggers eosinophil respiratory burst and spreading. Immunology 1993; 80: 273-280.

24. Neeley SP, Hamann KJ, Dowling TL, McAllister KT, White SR, Leff AR. Augmentation of stimulated eosinophil degranulation by VLA-4 (CD49d)-mediated adhesion to fibronectin. AM J Respir Cell Mol Biol 1994; 11: 206-213.

25. Yoshida K, Suko M, Matsuzaki G, Sugiyama M, Okudaira $\mathrm{H}$, Ito $\mathrm{K}$. Effect of fibronectin on the production of leukotriene $\mathrm{C} 4$ by eosinophils. Int Arch Allergy Immunol 1995; 108: Suppl. 1: 50-51.

26. Higashimoto I, Chihara J, Kakazu T, Yamamoto T, Kurachi D, Nakajima S. Adhesion to fibronectin augments eosinophil radical oxygen products. Int Arch Allergy Immunol 1995; 108: Suppl. 1: 48-49.

27. Chihara J, Kakazu T, Higashimoto I, Yamamoto T, Kurachi D, Nakajima S. Increased eosinophil oxidative metabolism by treatment with soluble intercellular adhesion molecule-1. Int Arch Allergy Immunol 1995; 108: Suppl. 1: 45-47.

28. Anwer ARF, Mogbel R, Walsh GM, Kay AB, Wardlaw AJ. Adhesion to fibronectin prolongs eosinophil survival. J Exp Med 1993; 177: 839-843.

29. Kita H, Ohnishi T, Okubo Y, Weiler D, Abrams JS, Gleich GJ. Granulocyte-macrophage colony stimulating factor and interleukin-3 release from human peripheral blood eosinophils and neutrophils. J Exp Med 1991; 174: 745-748.

30. Broide DM, Paine MM, Firestein GS. Eosinophils express interleukin 5 and granulocyte/macrophage colony stimulating factor mRNA at sites of allergic inflammation in asthmatics. J Clin Invest 1992; 90: 1414-1424.

31. Braun RK, Franchini M, Erard F, et al. Human peripheral blood eosinophils produce and release interleukin-8 on stimulating with calcium ionophore. Eur J Immunol 1993; 23: 956-960.

32. Miyamasu M, Hirai K, Takahashi Y, et al. Induction of eosinophil cytokine generation by chemoattractants. Int Arch Allergy Immunol 1995; 108: Suppl. 1: 12-15.

33. Rand TH, Cruikshank WW, Center DH, Weller PF. CD4 mediated stimulation of human eosinophils: lymphocyte chemoattractant factor and other CD4-binding ligands elicit eosinophil migration. J Exp Med 1991; 173: $1521-1528$

34. Saita N, Hirayama S, Sugimoto M, Ando M, Hirashima M. Chemotactic heterogeneity of eosinophils in idiopathic pulmonary eosinophilia. Int Arch Allergy Immunol 1995; 108 Suppl. 1: 25-27.

35. Aloui R, Gormand F, Prigent AF, Perrin-Fayolle M, Pacheco Y. Increased respiratory burst and phosphodiesterase activity in alveolar eosinophils in chronic eosinophilic pneumonia. Eur Respir J 1996; 9: 377-379. 